26 Schneck CD, Miklowitz DJ, Miyahara S, Araga M, Wisniewski S, Gyulai L, et al. The prospective course of rapid-cycling bipolar disorder: findings from the STEP-BD. Am J Psychiatry 2008; 165: 370-7.

27 McElroy SL, Weisler RH, Chang W, Olausson B, Paulsson B, Brecher M, et al. Double-blind, placebo-controlled study of quetiapine and paroxetine as monotherapy in adults with bipolar depression (EMBOLDEN II). J Clin Psychiatry 2010; 71: 163-74.

28 Sidor MM, McQueen's GM. Antidepressants for the acute treatment of bipolar depression: a systematic review and meta-analysis. J Clin Psychiatry 2011; 72: 156-67.

29 Peselow ED, Fieve RR, Difiglia C, Sanfilipo MP. Lithium prophylaxis of bipolar illness. The value of combination treatment. Br J Psychiatry 1994; 164 208-14

30 Altshuler L, Kiriakos L, Calcagno J, Goodman R, Gitlin M, Frye M, et al. The impact of antidepressant discontinuation versus antidepressant continuation on 1-year risk for relapse of bipolar depression: a retrospective chart review. J Clin Psychiatry 2001; 62: 612-6.

31 Bauer MS, Callahan AM, Jampala C, Petty F, Sajatovic M, Schaefer V, et al. Clinical practice guidelines for bipolar disorder from the Department of Veterans Affairs. J Clin Psychiatry 1999; 60: 9-21.

32 Suppes T, Calabrese J, Mitchell P, Pazzaglia P, Potter W, Zarin D. Algorithms for the treatment of bipolar manic-depressive illness. Psychopharmacol Bull 1995: 31: 469-74.

33 Frances AJ, Kahn DA, Carpenter D, Docherty JP, Donovan SL, The expert consensus guidelines for treating depression in bipolar disorder. J Clin Psychiatry 1998; 59 (suppl 4): 73-9.

34 Sachs GS, Printz DJ, Kahn DA, Carpenter D, Docherty JP. The Expert Consensus Guidelines: Medication Treatment of Bipolar Disorder 2000. A Postgraduate Medicine Special Report. The McGraw-Hill Companies, 2000.

\title{
Karl Jaspers and human-based psychiatry
}

\author{
Michael Musalek
}

We live in an incredibly fast-moving scientific world: what was valid yesterday is outdated today and perhaps long-forgotten tomorrow. The same applies to psychiatry. In the increasingly swift stream of psychiatric knowledge, one work stands out as a sheer immovable rock: Karl Jasper's General Psychopathology. What other medical work can lay claim to be just as topical and valid today as it was 100 years ago!

The quality of a scientific publication can be recognised by its impact on the world of research. With his work, Karl Jaspers not only succeeded in sending an unforgettable signal, he also created a source of strength for scientific research in psychiatry that even today has lost nothing of its power. This treasure trove of psychiatric knowledge also had an immeasurably strong impact on me personally. From the host of stimuli that I gained as a researcher and therapist, I would like to emphasise just two here: Jasper's elaborations on 'phenomenological intuition' and those which led to the more than justified demand for a 'psychopathology of the sick human individual' rather than a 'psychopathology of human sickness'.

Jaspers's demand that a sick individual should be approached using phenomenological intuition with a view to gaining a deeper understanding of his state of sickness stands in stark contrast to the superficial registration of characteristics of disease and their insertion into diagnostic algorithms that is prevalent today and which is focused on increasing the reliability of data that have been collected. As well as repeatedly opening up a new understanding of the state of being mentally ill, this phenomenological intuition, this going far beyond a mere empathetic engagement to a Being-in-the-World-of-the-Other, also opened up possibilities for developing a special form of hospitality in everyday psychiatric routines. The patient is no longer viewed as a person on the opposite side of the table who simply has to be treated according to the latest therapeutic guidelines, but as an other who is met in the diagnostic and therapeutic process on an equal footing in a genuine dialogue. The psychiatric treatment unit can thus become a meeting place that is characterised by lived reciprocal hospitality. The professional monologue, so rightly bemoaned by Michel Foucault, is replaced by a therapeutic dialogue that is based on reciprocity.

With the sentence: 'Psychopathology is concerned with the ill person as a whole, in so far as he suffers from psychic phenomena or those that are psychically determined', Karl Jaspers unequivocally tells us what our actual task as psychiatrists is. He stimulated me to think about a form of psychiatry which in recent years has been presented as human-based psychiatry. It is psychiatry based in postmodern maxims that overcome medical positivism and it permits the development and application of a multidimensional, differential-diagnostic process, which includes information not only about the patient's deficiencies, but above all information about their resources, thus opening the door for modular, resource-oriented treatment options. This kind of human-based psychiatry no longer aims just to make mental disorders disappear, but to enable patients to achieve a life that is as autonomous and happy as possible.

Professor Michael Musalek is General Director of the Anton Proksch Institute in Vienna. 